\title{
Cellulosic fibre drying: fundamental understanding and process modeling
}

Mondal, S.*; Agarwala, P.; Dutta, S.; Nimbalkar, V.; Pande, P.; Dhumal, S.

Aditya Birla Science \& Technology Company Private Limited, Navi Mumbai, India.

*E-mail of the corresponding author: sabyasachi.mondal@adityabirla.com

\begin{abstract}
Process modeling of conveyer dryer for cellulosic fibre drying demands many fundamental insights. Present study highlights detailed cellulosic fibre drying aspects like mass transfer correlation relating mass transfer rate with process conditions, normalized drying curve and critical moisture content. Cellulosic fibre drying follows falling rate period, where rate of mass transfer decreases with moisture content. Conveyer dryer process model for commercial cellulosic fibre drying was developed and validated successfully. Moderate drying strategy derived based on developed process model and drying fundamentals was deployed at commercial scale which helped in reducing the moisture variability.
\end{abstract}

Keywords: Cellulosic fibre, Conveyor dryer, Process Model, Sherwood number, Moderate drying. 


\section{Introduction}

Cellulosic fibres provide key attributes of comfort and softness to the final textile fabrics [1]. The widely used cellulosic fibres are cotton and man-made cellulosic fibres (viscose, lyocell, modal, etc.). Commercially all man-made cellulosic fibres are prepared by dissolving specific grades of pulp in a solvent, extruding into fibres followed by regeneration in a spin bath, cutting into specific lengths, web formation by steam/air sparging, treatment/washing and subsequently drying. The drying process is preceded by squeezing of fibre mat to remove excess water and opening the fibres in a mat opener. The drying process in case of cellulosic fibres, are pre dominantly carried out in hot air conveyer dryers to achieve desired moisture content in the final product [2]. Standard size (250 kg) bales are made out of dried fibres with a fibre meeting quality specs of 10.5- 11.5 wt. \% (dry basis) moisture content.

Low moisture variability and low levels of wet and over-dried fibres are key drivers to get good processibility and yarn quality in the downstream industry of converting fibres to yarn [3]. Major factors imparting variability are dryer inlet moisture variation and methodology adopted during drying operation. Precise control over dryer inlet moisture variability in cellulosic fibre was very difficult to achieve whereas effective control over dryer operation was the most practically feasible option. Improvement in fibre opening, mat uniformity, over drying followed by conditioning and control of air flow distribution inside the dryer by modifying the internal dryer design have been attempted historically [4]. These improvements alone have a limitation to reduce the variability, if not coupled effectively with control of operational parameters like air temperature, humidity and air distribution over fibre web. Mathematical modeling supported by specific product drying fundamentals, understanding of heat, mass and momentum aspects have also helped in getting effective control over moisture and its variability [5, 6, 7]. Efforts towards understanding the cellulosic fibre drying fundamentals and its use in commercial scale conveyer dryer process modeling to control the fibre quality forms the basis of this study as it was not reported in the literature.

A process model for commercial scale cellulosic fibre dryer was developed in Aspen, supported with data from understanding of cellulosic fibre drying fundamentals like drying rate curve, fibre critical moisture content and mass transfer correlation relating process parameters. Main goal of this study was to reduce moisture variability of cellulosic fibre at commercial scale with precise control in a narrow range (10.5-11.5 wt. \% on dry basis) and lower energy consumption during drying operation.

\section{Materials and methods}

Cellulosic fibre, in the form of viscose staple grey fibre, was used in this study from a leading man-made fibre manufacturer in India i.e. GRASIM industries. Commercial samples with 
standard fibre length (38 mm) and diameter $(45 \mu \mathrm{m})$ were chosen for the experimental studies to avoid raw material variability factor.

\subsection{Experimentation for fundamental understanding of drying}

Two separate experimental set-ups were developed to gather information for viscose fibre drying. First set-up was used to find out the drying kinetics and the second set-up to develop the correlation between mass transfer co-efficient and diffusivity. Developed fundamental understanding about drying kinetics and mass transfer correlation was used in Aspen model.

\subsection{1. $\quad$ Drying kinetics experiments}

Experiments were performed at different air temperatures $\left(80^{\circ} \mathrm{C}, 100^{\circ} \mathrm{C}, 120^{\circ} \mathrm{C}\right.$ and $\left.140^{\circ} \mathrm{C}\right)$ to find out the critical moisture content and drying rate curve of viscose staple fibre. Fully dried commercial viscose fibre samples were soaked in known water quantity for experimental purpose. Initial moisture of viscose fibre was at 300\% and maximum overall sample weight in individual experiment was chosen to be around $2 \mathrm{~g}$ based on analyzer limitations. Moisture analyzer continuously recorded moisture percentage and sample weight in every 30 seconds based on the thermo-gravimetric principle. Each experiment was repeated three times to check the repeatability.

\subsubsection{Mass transfer correlation experiments}

Drying kinetics is mainly driven by rate of mass and heat transfer coupled with momentum. A decreasing linear period with decreasing drying rate is generally happen after a critical point where drying rate is depended on drying conditions [8] similar to constant rate period. Therefore, mass transfer correlation was developed (Equation 1) using Sherwood number with air temperature $\left(\mathrm{T}_{\mathrm{G}},{ }^{\circ} \mathrm{C}\right)$, air absolute humidity (Y, kg moisture/kg dry air) and inlet fibre moisture content $\left(\mathrm{X}_{\mathrm{in}}, \mathrm{kg}\right.$ moisture/kg dry fibre).

$$
\mathrm{Sh}=\mathrm{f}\left(\mathrm{T}_{\mathrm{G}}, \mathrm{Y}, \mathrm{X}_{\mathrm{in}}\right)
$$

A separate set-up was developed where air of desired humidity (from air handling unit) was heated with the help of electric coils to raise the air temperature and wet viscose fibre sample was positioned at the bottom of the drying unit with cross-flow of hot air through fibre web/mat. Temperature and humidity sensors were placed in desired location of the setup to monitor the air quality. During experiments, air velocity was maintained at $0.6 \mathrm{~m} / \mathrm{s}$, similar to commercial dryer operation. Experiments were designed with three different air temperatures $\left(60,80\right.$ and $\left.100^{\circ} \mathrm{C}\right)$, four different moisture content of fibre sample $(20,40,70$ and 100 wt. \%) and three different absolute humidity conditions (0.022, 0.065 and $0.12 \mathrm{~kg} / \mathrm{kg}$ dry air). A total of forty-five set of experiments were planned for developing the mass transfer correlation, which was validated with five more random experiments. 


\subsection{Development of process model}

Fundamental understanding generated through experimental insights gave an idea about the preferable operational procedure. However, an optimum solution was essential to adopt in commercial plant operation. Aspen process simulation tool was used to predict the optimized solution with the help of experimentally generated basic data on viscose fibre drying.

Complete conveyor dryer (Fig. 1) was modeled with counter-current flow of air and viscose fibre, where each dryer zone was represented as a single dryer unit. Commercial conveyer dryer was divided into two sectional dryers, i.e. Dryer-A and Dryer-B, with further sub divisions of each sectional dryer. Fibre (solid) moved in axial (horizontal) direction with plug flow in each dryer, which operated at adiabatic saturation. NRTL (non-random two liquid) thermodynamic method was selected as a base method and STEAM-TA was opted for free water method as high pressure steam was used for air heating. A two stage heater-condenser arrangement was used to highlight the indirect air heating phenomena in Aspen.

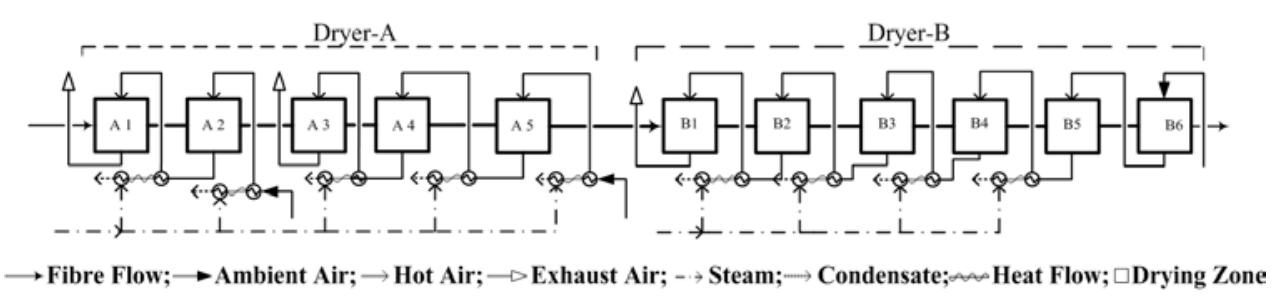

Fig. 1: Schematic representation of developed Aspen model: Multistage conveyor dryer

Mass and energy balance equations for both gas (air) and solid (fibre) phases were used in the background, which are inbuilt in Aspen [9]. Experimentally generated fundamentals, like mass transfer correlation, critical and equilibrium moisture content [10] and normalized drying rate with shape factor of viscose fibre were incorporated as input to Aspen model.

\section{Results and discussion}

\subsection{Drying curve: Viscose cellulosic fibre}

Drying rate curves were generated based on moisture data, as shown in Figure 2 (a), for viscose fibre at four different temperatures as per the procedure explained in section 2.1. Increase in drying temperature shows increase in drying rate, which diminishes towards end of drying i.e. at an equilibrium moisture content. Equilibrium moisture content of viscose staple fibre was around $8-12 \%$ for $30-60 \% \mathrm{RH}$ at $25^{\circ} \mathrm{C}$ [10]. 
Slope change of drying rate versus moisture content highlighted distinct periods like preheat zone, constant rate and falling rate period. Drying rate was observed to be very high at the preheat zone. Constant drying rate period typically follows preheat zone, due to continuous moisture availability at fibre surface where drying rate is controlled by heat transfer rate. Unavailability of moisture at the viscose fibre surface was observed in falling rate period where rate of moisture evaporation decreases with reduction in fibre moisture content. Transition from constant drying rate period to falling rate happens at a particular moisture content known as critical moisture content (Fig. 2a) which is $~ 130 \%$ for viscose fibre. Whereas in commercial/ plant scale fibre dryer inlet moisture $\sim 100 \%\left(<\mathrm{X}_{\mathrm{C}}\right)$ which depicts drying occurs in falling rate period.

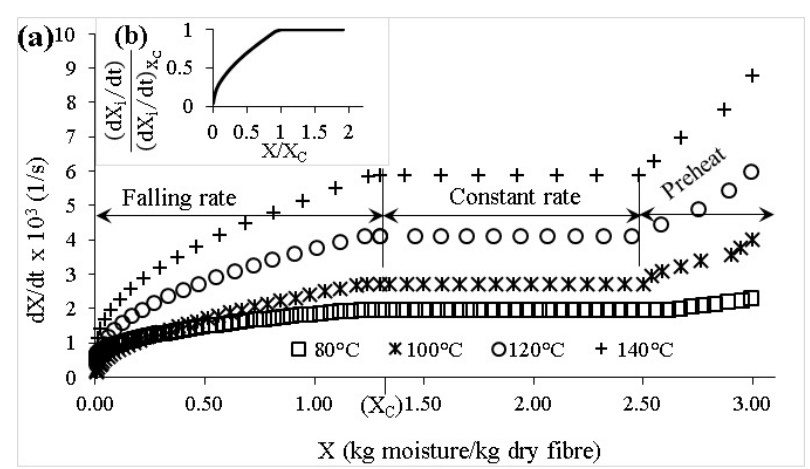

Fig. 2: Viscose staple fibre: (a) drying rate curve at different temperatures (Critical moisture content, $X_{C}=130 \%$ ) and (b) normalize drying rate verses normalize moisture content

Drying rate specification in Aspen is typically provided in the form of normalized average drying rate curve where individual drying rate was normalized with constant drying rate (Equation 2) and the individual moisture content was normalized with critical moisture content. Figure 2 (b) showed average normalized drying rate for viscose staple fibre, which was temperature independent. Drying rate shape factor (F) [9], Equation 2, was found to be around 'one' for viscose fibre.

$$
\vartheta(n)=\left(\frac{d x_{i}}{d t}\right) /\left(\frac{d x_{i}}{d t}\right)_{i=X_{C}}=2 . F \cdot\left(\frac{x}{x_{C}}\right)-(2 \cdot F-1)\left(\frac{x}{x_{C}}\right)^{2}
$$

\subsection{Mass transfer correlation with process parameters}

An attempt has been made here to understand the mass transfer rate aspects in commercial cellulosic fibre dryer. The rate of evaporation is proportional to moisture concentration gradient from fibre surface to air where proportionality constant is convective mass transfer coefficient where local mass transfer coefficient is proportional to Sherwood number 
Mostly, Sherwood number used to explain convective mass transfer. In case of porous material drying, two scenarios have observed in commercial dryer, one side moisture removal from fibre surface to air through convective mass transfer and in other side transportation of moisture from materials capillary to the surface through diffusion mass transfer which may lead to decreasing wetted surface drying [8]. A single stage convective drying unit model was used in Aspen to calculate the Sherwood number for each experiment to match the extent of drying rate for different input process parameters. A simplified predictive mass transfer correlation:

$$
\mathrm{Sh}=\mathrm{a}\left(\mathrm{T}_{\mathrm{G}}^{\mathrm{b}}\right)\left(\mathrm{e}^{\mathrm{g} \cdot \mathrm{Y}}\right)\left(\mathrm{e}^{\mathrm{h} \cdot \mathrm{X}_{\mathrm{in}}}\right)
$$

Statistical tool was used to estimate the constants with regression coefficient, $\mathrm{R}^{2}$ value of $74 \%$. Equation 4 shows a final version of mass transfer correlation using Sherwood number which was used in process model to estimate the local mass transfer coefficient of cellulosic (viscose) fibre and enhance the model robustness during optimization of drying.

$$
\mathrm{Sh}=\exp (-3.33) \cdot \mathrm{T}_{\mathrm{G}}{ }^{(-0.095)} \cdot \exp \left(0.9 . \mathrm{X}_{\mathrm{in}}\right) \cdot \exp (-(9.5 . \mathrm{Y}))
$$

Correlation clearly highlights proportional dependence on inlet fibre moisture content whereas air absolute humidity and temperature shows inverse with Sherwood number.

\subsection{Model validation}

Data from commercial production unit for outlet fibre moisture, steam/fibre ratio, exhaust air humidity, temperature, were used to validate the developed process model. Comparison of plant data and model predictions show maximum error of $7 \%$ whereas majority error numbers were $<5 \%$. In addition, it has been shown that the process model predicts the plant operational drying curve (Fig. 3), and also increases confidence in developed cellulosic fibre drying process model. Multiple model validation strongly confirms that the developed model is capable of predicting temperature profile with other operational parameters to get the desired moisture quality.

\subsection{Drying rate optimization for commercial conveyor dryer}

Cellulosic fibre mat thickness, of around $200 \mathrm{~mm}$, formed on the conveyer belt of the dryer significantly affects the moisture variation, as there exists no surface renewal mechanism in conveyor dryer except the effect induced by intermediate opener placed between Dryer-A and Dryer-B. Hot air flows in a cross flow manner through the moving fibre mat. Humidity starts occurring gain as air passes through the fibre mat with reduction in temperature and driving force for moisture removal. This phenomenon creates moisture variation within the mat and it continues till dryer end. Overall, drying rate has a potential to induce moisture variability at commercial scale and there is a scope for optimization of the same to reduce such variability. Commercially, first sectional dryer (Dryer-A) was operated at higher 
temperature to remove approximately $75 \%$ moisture with fast drying rate (Figure 3), whereas second sectional dryer (Dryer-B) removes around 15- 20\% of moisture at lower zone temperature. Mass transfer rate of moisture to the fibre surface along with available moisture carrying capacity of the hot air controls the overall drying operation.

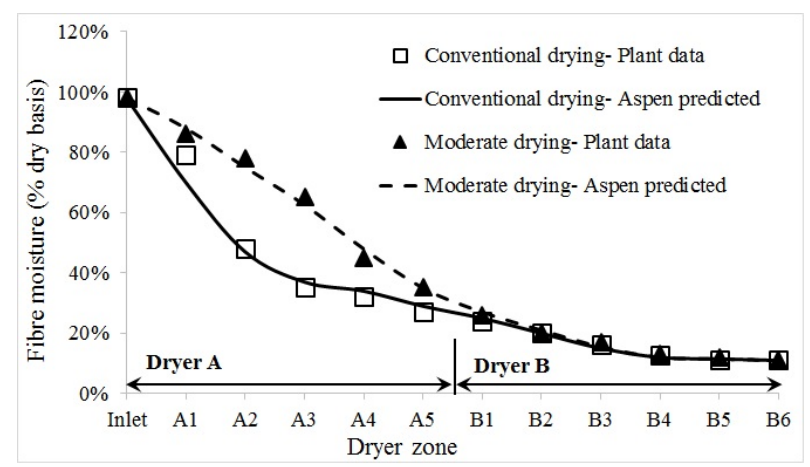

Fig. 3: Drying curve: Plant and Aspen predictions for conventional and moderate drying strategy

In a few initial zones, due to high moisture content, convective mass transfer rates are high due to sufficient moisture present at the fibre surface and air temperature creates enough driving force to remove the moisture. This phenomenon observed typically at early stage of falling rate period. After few zones, transportation of moisture from capillary to fibre surface is dominated by diffusion where moisture evaporation happens at decreasing rate. Drying rate decreases with decrease of moisture content. Also, correlation (Equation 4) clearly shows higher Sherwood number at initial stage due to the impact of convective mass transfer and lower value of Sherwood number after few initial zones was due to lower convection mass transfer where impact of diffusion on drying process is high. Facilitation of the diffusion process to overcome capillary forces demands raising the fibre surface temperature. Overall fundamental insights along with multipoint validation provided confidence to deploy process model predictions of optimum parametric combination known as moderate drying strategy for targeting moisture variability reduction.

Figure 3 shows the comparison between drying curve of conventional (fast) and moderate drying strategy along with model predicted. In the moderate drying strategy, drying curve is shifted upwards compared to conventional due to lower temperatures adopted the initial zones. Disappearance of this shift occurs at the start of Dryer-B due to higher temperatures adopted during start of Dryer-B which increases the fibre surface temperatures by $\sim 10^{\circ} \mathrm{C}$ higher than conventional. Developed moderate drying strategy is adopted in commercial 
plant and improved in-spec bales by $18 \%$ (from $63 \%$ to $81 \%$ ) within narrow range (10.5$11.5 \%$ ) by reduction in moisture variability along with $9 \%$ reduction in steam consumption.

\section{Conclusion}

A fundamental understanding of cellulosic fibre (viscose) drying was obtained in terms of critical moisture content, normalized drying curve and mass transfer correlation. Commercial viscose fibre drying operation falls under falling rate period where convective mass transfer along with diffusion limits the moisture removal. Conveyer dryer process model for commercial viscose fibre drying was developed and validated successfully. Model suggested optimum process parameter combination maintained during drying operation at commercial scale reduced moisture variability by $18 \%$ along with steam consumption reduction of $9 \%$.

\section{Acknowledgement}

This work is supported by Grasim Industries, Aditya Birla Group. Authors are thankful to ABSTCPL leadership and other team members for their valuable inputs during this project.

\section{References}

[1] Ahmat, C. Modelling of the Drying Behaviour of Regenerated Cellulosic Fabrics. Tekstil ve Konfeksiyon 2017, 27 (4), 373-381.

[2] Lisyakova, G.V.; Serkov, A.T.; Tsyganov, K.I. Drying and Conditioning of Viscose Staple Fibre. Khlmicheskle Volokna 1986, 6, 28-32.

[3] Uyanik, S.; Baykal, P.D. Effects of Fibre Types and Fibre Blends Ratio on Vortex Yarn Properties. The Journal of the Textile Institute 2017, 108.

[4] Jamaleddine, T. J; Ray, M. Application of Computational Fluid Dynamics for Simulation of Drying Processes: A Review. Drying Technology 2010, 28, 120-154.

[5] Pang, S. Mathematical Modelling of MDF Fibre Drying: Drying Optimization. Drying Technology 2000, 18 (7), 1433-1448.

[6] Fritzell, E.; Melander, O.; Rasmuson, A. The Drying Kinetics and Equilibrium Moisture Content. Drying Technology 2009, 27, 993-998.

[7] Mujumdar, A.S.; Fundamental Aspects. In Handbook of Industrial Drying. 3, Lodz, Poland; Taylor \& Fransis Group, LLC, 2014; 4-31.

[8] Belhamri, A.; Characterization of the First Falling Rate Period During Drying of Porous Material. Drying Technology 2003, 21(7), 1235-1252.

[9] Levine, J.; Lakshmanan, A.; Peers, Z. Jump Start: Modeling Convective Dryers in Aspen Plus V8.0, Aspen Technology, 2013.

[10] Sousa, L.H.C.D.; Pereira, N.C.; Motta Lima, O.C.; Fonseca, E.V. Equilibrium Moisture Isotherms of Textiles Materials. Maringá 2001, 23(6), 1363-1368. 